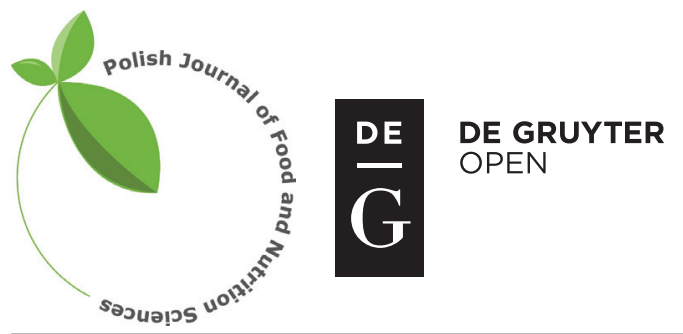

Pol. J. Food Nutr. Sci., 2016, Vol. 66, No. 3, pp. 221-226

DOI: $10.1515 /$ pjfns-2015-0049 http://journal.pan.olsztyn.pl

Original article

Section: Nutrition Section

\title{
Longer Breastfeeding in Infancy Decreases Systolic Hypertension Risk in Young Adults
}

\author{
Karolina Rak ${ }^{1 *}$, Danuta Kornafel ${ }^{2}$, Monika Bronkowska $^{1}$ \\ ${ }^{1}$ Department of Human Nutrition, Faculty of Food Science, Wroclaw University of Environmental and Life Sciences, \\ ul. Chetmońskiego 37, 51-630 Wroctaw, Poland \\ ${ }^{2}$ Department of Psychology, Faculty of Pedagogical Sciences, University of Lower Silesia, \\ ul. Wagonowa 9, 53-609 Wroctaw, Poland
}

Key words: cardiovascular risk, blood pressure, hypertension, overweight, obesity

Many studies show that breastfeeding is associated with numerous direct and indirect health benefits for children in later life, although the relationship between breastfeeding and cardiovascular risk is still equivocal. The aim of this study was to investigate the relationship between duration of breastfeeding and cardiovascular risk in young adults. The cross-sectional study was conducted on a group of 128 volunteers (71 women and 57 men) at the age of 19 years. It consisted of a questionnaire, together with anthropometric and blood pressure measurements. It was demonstrated that $90.3 \%$ of the participants had been breastfed and the mean duration of breastfeeding was $8.8 \pm 7.6$ months. Participants who were breastfed for longer than six months had a significantly lower systolic blood pressure than those breastfed for less than six months. Results of analyses were consistent for the female group, the male group and the combined group. The results suggest that breastfeeding for longer than six months decreases systolic hypertension risk in young adults. The promotion of breastfeeding may decrease the rate of cardiovascular disease and thus improve health status of the population.

\section{INTRODUCTION}

Cardiovascular diseases (CVD) are a major health problem and the most common cause of death in the world. The main CVD risk factor is raised blood pressure followed by overweight and obesity, raised blood cholesterol and lipids, raised blood glucose (diabetes), tobacco use, insufficient physical activity, and unhealthy diet [WHO, 2011].

According to nutritional programming theory, nutrient deficiency or excess during critical periods of development leads to irreversible changes in metabolism as well as to structural modifications affecting health status in later life [Barker, 1995; Schmid et al., 2009; Gruszfeld et al., 2011]. The critical period certainly includes fetal life, when rapid growth is susceptible to any changes in nutrient availability [Gruszfeld et al., 2011; Agostoni et al., 2013]. Insufficient supply of nutrients during this period results in low birth weight (LBW), permanent changes in lipid metabolism and fat storage, and elevated plasma cortisol levels [Phillips et al., 2000; Gruszfeld et al., 2011]. Other consequences include permanent reduction of the mass of muscle cell, nephrons, hepatocytes and pancreatic beta cells [Boyko, 2000; Gruszfeld et al., 2011]. Because of these effects, LBW infants are more likely to have CVD and metabolic syndrome in later life [Godfrey \& Barker, 2000; Phillips et al., 2000; Boyko, 2000; Barker et al., 2002]. It seems that nutritional programming of metabolism

\footnotetext{
* Corresponding Author: karolina.rak@up.wroc.pl (K. Rak)

occurs not only in fetal life, but also in infancy when growth is still rapid [Gruszfeld et al., 2011; Agostoni et al., 2013]. There is increasing number of studies on how nutrition during the first two years of life affects later health outcomes. However, the association between nutrition in infancy and CVD risk has not yet been definitively confirmed.

In this paper, only breastfeeding as the earliest nutrition pattern in infancy is considered. Breast milk is a perfectly balanced food for an infant and contains all of the essential nutrients in suitable amounts. Compared to infant formula, breast milk contains less protein, higher fat quality and more prebiotics [Heinig et al., 1993; Boehm \& Stahl, 2007; Koletzko et al., 2011]. Furthermore, human milk regulates the infant's sense of hunger and satiety, probably by affecting leptin and ghrelin levels [Agostoni, 2005; Li et al., 2010]. WHO recommends exclusive breastfeeding for up to six months of the newborn's life, and continuing breastfeeding with complementary food for up to two years [WHO, 2001].

Studies report mixed results on the impact of breastfeeding on CVD risk. Some show no association [Ravelli et al., 2000; Leeson et al., 2001; Burdette et al., 2006; Holmes et al., 2010]. Others, however, indicate that infants who were breastfed (compared to non-breastfed), were breastfed longer (compared to breastfed shorter) and had been later introduced complementary food are less likely to be overweight and obese, and less likely to suffer from hypertension, dyslipidemia and diabetes [Ip et al., 2007; Parikh et al., 2009; Fall et al., 2011; McCrory \& Layte 2012; Owen et al., 2002, 2003, 
2008; Martin et al., 2005]. This suggests that breastfeeding decreases the risk of metabolic syndrome and non-communicable disorders in childhood, adolescence and adulthood [Agostoni et al., 2013]. However, this association has not yet been definitively confirmed.

The aim of this study is to investigate the association between the breastfeeding duration and following CVD risk factors in young adults: systolic and diastolic blood pressure (SBP, DBP) and overweight/obesity (BMI), especially visceral type (WHR, WHtR). We hypothesize that breastfeeding period longer than six months is connected with lower values of the examined indicators of CVD risk and thus it may at least partially decrease CVD risk.

\section{MATERIALS AND METHODS}

\section{Study group}

The present cross-sectional study was conducted on a group of 128 19-year-old students, 71 women and 57 men, born in 1993 and in the final year of three secondary schools in Wroclaw, Poland.

\section{Procedures}

After permission was received from the schools enlisted, 655 questionnaires were distributed in their coverage areas, 353 to women and 302 to men. The response rate was $29.8 \%$. In total, 195 students gave their oral informed consent to be volunteers in the study. They were fully informed about the purpose and the procedure of this study, and that they could withdraw at any stage. The study followed principles in the Declaration of Helsinki.

The study consisted of a questionnaire, as well as anthropometric and blood pressure measurements. The questionnaire contained questions about newborn parameters (sex, birth weight, gestational age, type of delivery and birth order), early nutrition patterns (duration of breastfeeding), social status of the family (parental education and place of residence), current health condition (subjective assessment) and lifestyle habits (smoking, physical activity and diet). Participants completed the questionnaire at home. They were instructed to fill out the section on breastfeeding and newborn parameters contained in health records with the help of their parents.

After the completed questionnaires were given back to researchers, 67 respondents were excluded from the study due to lack of necessary information in the questionnaire, low birth weight (less than $2500 \mathrm{~g}$ ) and high birth weight (more than $4000 \mathrm{~g}$ ). Normal birth weight (2500-4000 g) was a requirement of inclusion in the study. Low birth weight as well as high birth weight is connected with elevated risk of CVD since U-shaped association between birth weight and increased risks of developing hypertension and other metabolic disorders in later life is observed in women [Curhan et al., 1996a] and men [Curhan et al., 1996b]. Excluding these individuals allowed to avoid the independent effect of birth weight on the CVD risk factors examined. Finally, 128 volunteers participated in the study, including 71 women and 57 men.

Volunteers were examined in school nurse's office. The following data were recorded: systolic blood pressure
(SBP), diastolic blood pressure (DBP), height, weight, waist circumference (WC) and hip circumference.

\section{Determination of CVD risk factors}

The following CVD risk factors in young adults were investigated: systolic and diastolic blood pressure (SBP, DBP) and overweight/obesity (BMI), especially visceral type (WC,WHR, WHtR). Blood pressure was measured twice in two-minute intervals with an oscillometric blood pressure meter. The procedure of blood pressure measurement was conducted according to the standards adopted in medical sciences (appropriate location of a cuff, body position and time for rest and calming the breath before the measurement) [Kułaga et al., 2010]. Subsequently, height, weight, waist circumference, and hip circumference were measured. Before anthropometric measurements were taken, participants were asked to strip down to their underwear. Height was measured to the nearest $0.1 \mathrm{~cm}$ with an anthropometer. Weight was measured to the nearest $0.5 \mathrm{~kg}$ with a mechanical scale. Circumferences were measured to the nearest $0.5 \mathrm{~cm}$ with an anthropometric measuring tape. The procedure of anthropometric measurements including body position and instruments location was conducted according to the standards adopted in anthropometry [Malinowski \& Boziiłow, 1997]. Based on these measurements, the following ratios were calculated: body mass index (BMI), waist-to-hip ratio (WHR) and waistto-height ratio (WHtR). CVD risk factors in the volunteers examined are presented in Table 1.

\section{Determination of breastfeeding duration}

Information about total duration of breastfeeding was given by participants' mothers in the questionnaire. These data can be considered valid and reliable as studies showed that the difference between the maternal recall of breastfeeding duration and validation standard is very slight [Li et al., 2005]. Criteria for breastfeeding were defined as at least one meal in the form of mother's milk. Breastfeeding was originally recorded in months, and subsequently categorized into two categories: breastfed for one to six months and breastfed for more than six months.

TABLE 1. CVD risk factors among young adults in Wroclaw, Poland $(\mathrm{N}=128)$.

\begin{tabular}{l|cc|c|c}
\hline \multirow{2}{*}{$\begin{array}{l}\text { CVD } \\
\text { risk factors }\end{array}$} & \multicolumn{2}{|c|}{ Women $(\mathrm{N}=71)$} & \multicolumn{2}{c}{ Men $(\mathrm{N}=57)$} \\
\cline { 2 - 5 } & $\begin{array}{c}\text { Mean } \\
\pm \text { SD }\end{array}$ & Range & $\begin{array}{c}\text { Mean } \\
\pm \mathrm{SD}\end{array}$ & Range \\
\hline BMI $\left(\mathrm{kg} / \mathrm{m}^{2}\right)$ & $20.7 \pm 2.7$ & $16.1-30.3$ & $22.7 \pm 2.8$ & $16.1-31.2$ \\
WHR & $0.73 \pm 0.04$ & $0.66-0.85$ & $0.80 \pm 0.04$ & $0.73-0.91$ \\
WC $(\mathrm{cm})$ & $70.1 \pm 6.6$ & $58-95$ & $79.6 \pm 6.5$ & $69-94$ \\
WHTR & $0.42 \pm 0.04$ & $0.36-0.57$ & $0.45 \pm 0.04$ & $0.39-0.55$ \\
SBP (mmHg) & $113.6 \pm 10.3$ & $83-133$ & $130.8 \pm 12.6$ & $99-157$ \\
DBP (mmHg) & $73.1 \pm 10.6$ & $45-98$ & $76.4 \pm 10.8$ & $57-115$ \\
\hline
\end{tabular}

CVD: cardiovascular disease; BMI: body mass index; WHR: waist-to-hip ratio; WC- waist circumference; WHtR- waist-to-height ratio; SBP: systolic blood pressure; DBP: diastolic blood pressure. 
TABLE 2. Association between breastfeeding duration and cardiovascular risk factors in the combined groups and in the separate group of young women and men in Wroclaw, Poland $(\mathrm{N}=128)$.

\begin{tabular}{|c|c|c|c|c|c|c|c|c|}
\hline \multirow{2}{*}{ CVD risk factors } & \multicolumn{3}{|c|}{ Breastfed for $1-6$ months } & \multicolumn{3}{|c|}{ Breastfed for more than 6 months } & \multirow{2}{*}{ M-W } & \multirow{2}{*}{ p-value } \\
\hline & $\mathrm{N}$ & Mean & SD & $\mathrm{N}$ & Mean & SD & & \\
\hline \multicolumn{9}{|c|}{ Combined group $(\mathrm{N}=128)$} \\
\hline BMI & 50 & 21.64 & 3.00 & 78 & 21.53 & 2.84 & 0.144 & 0.885 \\
\hline WHR & 50 & 0.76 & 0.05 & 78 & 0.76 & 0.05 & 0.772 & 0.440 \\
\hline WC & 50 & 74.73 & 8.48 & 78 & 74.08 & 7.83 & 0.335 & 0.738 \\
\hline WHtR & 50 & 0.43 & 0.04 & 78 & 0.43 & 0.04 & 0.813 & 0.416 \\
\hline SBP & 50 & 124.48 & 15.49 & 78 & 119.26 & 13.09 & 2.007 & $0.045^{*}$ \\
\hline DBP & 50 & 75.26 & 12.03 & 78 & 74.12 & 9.97 & -0.466 & 0.641 \\
\hline \multicolumn{9}{|c|}{ Women $(\mathrm{N}=71)$} \\
\hline BMI & 30 & 20.70 & 3.06 & 41 & 20.71 & 2.39 & -0.518 & 0.604 \\
\hline WHR & 30 & 0.74 & 0.04 & 41 & 0.72 & 0.04 & 1.233 & 0.217 \\
\hline WC & 30 & 70.63 & 7.44 & 41 & 69.67 & 5.94 & 0.285 & 0.775 \\
\hline WHtR & 30 & 0.42 & 0.04 & 41 & 0.42 & 0.03 & 0.192 & 0.848 \\
\hline SBP & 30 & 116.57 & 11.59 & 41 & 111.49 & 8.88 & 2.305 & $0.021^{*}$ \\
\hline DBP & 30 & 72.40 & 11.10 & 41 & 73.54 & 10.30 & 0.407 & 0.684 \\
\hline \multicolumn{9}{|c|}{$\operatorname{Men}(\mathrm{N}=57)$} \\
\hline BMI & 20 & 23.06 & 2.33 & 37 & 22.44 & 3.05 & -1.212 & 0.225 \\
\hline WHR & 20 & 0.81 & 0.04 & 37 & 0.79 & 0.04 & -0.961 & 0.336 \\
\hline WC & 20 & 80.88 & 5.88 & 37 & 78.96 & 6.73 & -1.221 & 0.222 \\
\hline WHtR & 20 & 0.45 & 0.03 & 37 & 0.44 & 0.04 & 1.379 & 0.168 \\
\hline SBP & 20 & 136.35 & 12.90 & 37 & 127.86 & 11.59 & -2.216 & $0.027^{*}$ \\
\hline DBP & 20 & 79.55 & 12.36 & 37 & 74.76 & 9.69 & -1.522 & 0.128 \\
\hline
\end{tabular}

* statistically significant ( $\mathrm{p} \leq .05)$; CVD: cardiovascular disease; BMI: body mass index; WHR: waist-to-hip ratio; WC- waist circumference; WHtR: waist-to-height ratio; SBP: systolic blood pressure; DBP: diastolic blood pressure; M-W: Mann-Whitney test.

\section{Data analysis}

The association between duration of breastfeeding and cardiovascular risk factors was evaluated using the Mann-Whitney test in combined as well as separate groups of women and men. The normality of the distribution was evaluated using the Kolmogorov-Smirnov test, the Lilliefors test and the Shapiro-Wilk test. The homogeneity of variances was evaluated using the Levene test. Statistical analyses were conducted with the help of the STATISTICA 10 PL software package. For all analyses, $p \leq 0.05$ was considered significant.

\section{Control variables}

Control variables which are possible confounding factors were chosen based on the literature. These are following: sex [Kim \& Reaven, 2013], gestational age [Crump et al., 2011], type of delivery [Goldani et al., 2013; Mesquita et al., 2013], maternal education [Lakshman et al., 2013], smoking [Virdis et al., 2010], physical activity [Myers, 2003], and quality of the diet [Swinburn et al., 2004].
Gestational age was recorded as pre-term, term or post-term. Type of delivery was recorded as natural or cesarean section. Maternal education was recorded as elementary/ vocational, secondary or tertiary. Smoking was recorded as non-smoking, occasional smoking or smoking. Physical activity was recorded as none, 1 to 2 hours a week, 3 to 4 hours a week or more than 4 hours a week. Quality of the diet was assessed as low, medium or high based on the frequency of consumption of breakfast and four groups of food products: fruits \& vegetables, fast-food, sweets and sugary drinks. Frequency of consumption was recorded in five categories: never, occasionally, several times a week and once a day, and several times a day. Breakfast and fruits \& vegetables were considered as beneficial elements of the diet. Fast-food, sweets and sugary drinks were considered as detrimental elements. The more often beneficial elements were consumed, the more positive points were given: several times a week +1 , once a day +2 , and several times a day +3 . The more often detrimental elements products were consumed, the more negative points were given: several times a week -1, once a day -2 , 
and several times a day -3 . Not eating beneficial elements was given a score of -2 points, and occasional eating of beneficial elements was given a score of -1 point. Not eating detrimental elements was given a score of +2 points, and occasional eating of detrimental elements was given a score of +1 point. The points were added together, and the resulting scale from -13 to +11 was divided into tertiles, which made it possible to estimate the quality of the diet as low, medium and high. Diet analysis has been developed by the authors.

Information relating to analyzed variables was obtained from the questionnaire. Chi-square tests were conducted to examine if these variables are distributed uniformly in the subgroups (breastfed for 1 to 6 months and breastfed for more than 6 months). Random selection of all analyzed variables was confirmed at $p>0.05$. These factors may thus be considered as controlled, that is, CVD risk factors did not differ between the two subgroups. Additionally, age (only 19-year-old participants), education level (only graduating classes from secondary schools) and birth weight (only normal birth weight) of participants were strictly controlled.

\section{RESULTS}

Collected data showed that $90.3 \%$ of the 195 respondents $(88.6 \%$ of the women and $92.6 \%$ of the men) had been breastfed, and the mean duration of breastfeeding was $8.8 \pm 7.6$ months.

The results of the Mann-Whitney test on the final sample of 128 students carried out to evaluate the association between duration of breastfeeding and cardiovascular risk factors are reported in Table 2.

In the combined group, volunteers who were breastfed for longer than six months had significantly lower SBP than those who were breastfed for one to six months $(p=0.045)$. The difference in SBP was not only statistically relevant, but also clinically relevant. Volunteers breastfed for longer than six months had normal blood pressure, whereas those breastfed for less than six months had pre-hypertension.

After separating the combined group by sex, in the female group as well as in the male group the SBP was significantly lower in students breastfed for longer than six months ( $p=0.021$ and $p=0.027$, respectively). However, in contrast to the combined group, in the female group and the male group, the difference in SBP was not clinically relevant. Mean blood pressure was normal in women and pre-hypertensive in men regardless of breastfeeding duration.

The other cardiovascular risk factors, BMI, WHR, WC, WHtR and DBP, did not differ significantly between the two examined subgroups.

\section{DISCUSSION}

The study demonstrated that $90.3 \%$ of the respondents were breastfed, and the mean duration of breastfeeding was $8.8 \pm 7.6$ months. This is consistent with results reported by the Central Statistical Office, which show that $86.3 \%$ of Polish infants in 2009 were breastfed and two-thirds of this group was breastfed for six months or longer [Central Statistical Office, 2011]. Similar rates of breastfeeding were re- ported in a 2008 study on infants in Germany and France [Walburg et al., 2010].

In the present study, volunteers who were breastfed for longer than six months had significantly lower SBP than those who were breastfed for one to six months. Consistent results were obtained in the analysis in the combined group as well as in the female group and the male group assessed separately.

The findings of other studies are not clear. Meta-analyses performed by Martin et al. [2005] and Owen et al. [2003] found that breastfed infants had lower SBP and DBP than bottle-fed infants. Fewtrell [2011] also showed that breastfed infants had lower blood pressure in adolescence than non-breastfed infants. However, there are studies which do not support these results. Fall et al. [2011] stated that longer breastfeeding does not protect against hypertension. No association between breastfeeding and adult blood pressure was detected by Ravelli et al. [2000], Leeson et al. [2001] and Parikh et al. [2009].

Results of studies on the association of breastfeeding and adiposity are also equivocal. Parikh et al. [2009] found that infants from the United States who were ever breastfed had a lower BMI in adulthood than those who were never breastfed. Michels et al. [2007] and Gillman et al. [2006] reported that there was an inverse association between breastfeeding duration in infancy and adiposity in American adolescents and adults. McCrory \& Layte [2012] showed that being breastfed for between 13 and 25 weeks was associated with a 38 percent reduction in the risk of being overweight or obese at nine-years of age, while being breastfed for 26 weeks or more was associated with 51 percent reduction. On the other hand, Izadi et al. [2013] did not find any association between duration of breastfeeding and the risk of being overweight or obese in over five thousand Iranian students. Based on studies conducted in low-income and middle-income countries, Fall et al. [2011] also established that duration of breastfeeding was not associated with adult adiposity, but that introduction of complementary food later in childhood significantly reduced BMI and WHR. These authors suggest that it is the duration of exclusive breastfeeding that protects against cardiovascular disease in adulthood, and not the total duration of breastfeeding.

The present study has several limitations. The first one is cross-sectional nature of the study resulting in lack of the history of the volunteers' biological development including anthropometrical, physiological and biochemical parameters, life style habits, living conditions or other factors important for current health condition, including CVD risk. The second one is lack of details on early nutrition patterns in infancy such as duration of exclusive breastfeeding, quality of complementary feeding and quantity of different nutrients in an infant diet. Some studies showed that it may be significant for health status in later life [Agostoni et al., 2013]. Another limitation is lack of biochemical markers like blood glucose or blood cholesterol which are also important CVD risk factors. Finally, our sample was moderately large.

On the other hand, the strong point of this study was that we could control for possible confounding factors including maternal education, newborn parameters, modifiable CVD risk factors such as physical activity, diet and smoking (life style habits) as well as non-modifiable CVD risk factors like 
sex and age. Perhaps most importantly, we were able to strictly control for birth weight by including in the analysis only subjects with normal birth weight. In this way, we avoided the confounding effect of fetal nutritional programming on CVD risk factors in the volunteers examined [Godfrey \& Barker 2000; Barker et al., 2002].

Due to limitations of this study and also mixed results and equivocal opinions in this research area presented in worldwide literature, further studies are needed to clarify the association between breastfeeding and CVD risk factors. These include longitudinal studies conducted on large groups of participants that examine early nutrition patterns in infancy in detail, anthropometric and physiological measurements as well as blood chemistry to comprehensively assess CVD risk. Results cannot be generalized because of large number of non-responders. Further studies are needed to improve the number of responders and increase the possibility of generalizing study results.

\section{CONCLUSION}

In conclusion, our results support the hypothesis that longer breastfeeding may at least partially decrease cardiovascular risk. Consequently, infants who were breastfed for a short time may have an elevated risk of cardiovascular disease. Studies report mixed results and equivocal opinions in this research area, so further investigations are needed to clarify the association between breastfeeding and CVD risk factors.

\section{ACKNOWLEDGEMENTS}

Authors would like to thank Mrs. Monika Krawczykowska for help in material collecting.

\section{RESEARCH FUNDING}

Publication supported by Wroclaw Centre of Biotechnology, programme The Leading National Research Centre (KNOW) for years 2014-2018.

\section{CONFLICT OF INTEREST}

None declared.

\section{REFERENCES}

1. Agostoni C., Ghrelin, leptin and the neurometabolic axis of breastfed and formula-fed infants. Acta Paediatr., 2005, 94, 523-525.

2. Agostoni C., Baselli L., Mazzoni M.B., Early nutrition patterns and diseases of adulthood: A plausible link? Eur. J. Intern. Med., 2013, 24, 5-10.

3. Barker D.J.P., Fetal origins of coronary heart disease. Brit. Med. J, 1995, 311, 171-174.

4. Barker D.J.P., Eriksson J.G., Osmond C., Fetal origins of adult disease: strength of effects and biological basis. Int. J. Epidemiol., 2002, 31, 1235-1239.

5. Boehm G., Stahl B., Oligosaccharides from milk. J. Nutr., 2007, $137,847-849$
6. Boyko E., Proportion of type 2 diabetes resulting from impaired fetal growth. Diab. Care, 2000, 23, 1260-1264.

7. Burdette H.L., Whitaker R.C., Hall W.C., Daniels S.T., Breastfeeding, introduction of complementary foods and adiposity an $5 \mathrm{y}$ of age. Am. J. Clin. Nutr., 2006, 83, 550-558.

8. Central Statistical Office. Health of children and youth in Poland in 2009. Studies and statistical analyses. Kraków, 2011 (in Polish).

9. Crump C., Winkleby M.A., Sundquist K., Sundquist J., Risk of hypertension among young adults who were born preterm: A Swedish National Study of 636,000 Births. Am. J. Epidemiol., 2011, 173, 797-803.

10. Curhan G.C., Chertow G.M., Willett W.C., Spiegelman D., Colditz G.A., Manson J.E., Speizer F.E., Stampfer M.J., Birth weight and adult hypertension and obesity in women. Circulation, 1996a, 94, 1310-1315.

11. Curhan G.C., Willett W.C., Rimm E.B., Spiegelman D., Ascherio A.L., Stampfer M.J., Birth weight and adult hypertension, diabetes mellitus, and obesity in US men. Circulation, 1996b, 94, 3246-3250.

12. Fall C.H.D., Borja J.B., Osmond C., Richter L., Bhargava S.K., Martorell R., Stein A.D., Barros F.C., Victoria C.G., COHORTS group, Infant-feeding patterns and cardiovascular risk factors in young adulthood: data from five cohorts in low- and middle-income countries. Int. J. Epidemiol., 2011, 40, 47-62.

13. Fewtrell M.S., Breast-feeding and later risk of CVD and obesity: evidence from randomized trials. Proc. Nutr. Soc., 2011, 70, 472-477.

14. Gillman M.W., Rifas-Shiman S.L., Berkey C.S., Lindsay A., Frazier A.L., Rockett H.R., Camargo Jr. C.A., Field A.E., Colditz G.A., Breast-feeding and overweight in adolescence: within family analysis. Epidemiology, 2006, 17, 112-114.

15. Godfrey K.M., Barker D.J.P., Fetal nutrition and adult disease. Am. J. Clin. Nutr., 2000, 71, 1344-1352.

16. Goldani M.Z., Barbieri M.A., Silva A.A.M., Gutierrez M.R.P., Bettiol H., Goldani H.A.S., Cesarean section and increased body mass index in school children: two cohort studies from distinct socioeconomic background areas in Brazil. Nutr. J., 2013, 12, 104.

17. Gruszfeld D., Socha P., Niemirska A., Litwin M., Nutritional programming. Standardy Medyczne, 2011, 6, 885-888 (in Polish).

18. Heinig M.J., Nommsen L.A., Peerson J.M., Lonnerdal B., Dewey K.G., Energy and protein intakes of breast-fed and formula-fed infants during the first year of life and their association with growth velocity: the DARLING Study. Am. J. Clin. Nutr., 1993, 58, 152-161.

19. Holmes V.A., Cardwell C., McKinley M.C., Young I.S., Murray L.J., Boreham C.A., Woodside J.V., Association between breastfeeding and anthropometry and CVD risk factors status in adolescence and young adulthood: the Young Hearts Project, Northern Ireland. Public Health Nutr., 2010, 13, 771-778.

20. Ip S., Chung M., Raman G., Chew P., Magula N., DeVine D., Trikalinos T., Lau J., Breastfeeding and maternal and infant health outcomes in developed countries. Evid. Rep.- Technol. Assess., 2007, 153,1-186.

21. Izadi V., Kelishadi R., Qorbani M., Motlagh M.E., Taslimi M., Heshmat R., Ardalan G., Azadbakht L., Duration of breast-feeding and cardiovascular risk factors among Iranian children and adolescents: The CASPIAN III study. Nutrition, 2013, 29, 744-751.

22. Kim S.H., Reaven G., Sex differences in insulin resistance and cardiovascular disease risk. J. Clin. Endocr. Metab., 2013, 98, 1716-1721. 
23. Koletzko B., Agostoni C., Bergmann R., Ritzenthaler K., Shamir R., Physiological aspects of human milk lipids and applications for infant feeding: a workshop report. Acta Paediatr., 2011, 100, $1405-1415$.

24. Kułaga Z., Litwin M., Grajda A., Kułaga K., Gurzkowska B., Pan H., OLAF Study Group, Distribution of values of arterial blood pressure in reference population of schoolchildren. Standardy Medyczne/Pediatria, 2010, 7, 100-111 (in Polish).

25. Lakshman R., Zhang J., Zhang J., Koch F.S., Marcus C., Ludvigsson J., Ong K.K., Sobko T., Higher maternal education is associated with favourable growth of young children in different countries. J. Epidemiol. Commun. H., 2013, 67, 595-602.

26. Leeson C.P., Kattenhorn M., Deanfield J.E., Lucas A., Duration of breast feeding and arterial distensibility in early adult life: population based study. Brit. Med. J, 2001, 322, 643-647.

27. Li R., Scanlon K.S., Serdula M., The validity and reliability of maternal recall breastfeeding practice. Nutr. Rev., 2005, 63, 103-110.

28. Li R., Fein S.B., Grummer-Strawn L.M., Do infants fed from bottles lack self-regulation of milk intake compared with directly breastfed infants? Pediatrics, 2010, 125, 1386-1393.

29. Malinowski A., Bożiłow W., Podstawy antropometrii: metody, techniki, normy. 1997, PWN, Warszawa, Łódź (in Polish).

30. Martin R.M., Gunnell D., Smith G.D., Breastfeeding in infancy and blood pressure in later life: systematic review and meta-analysis. Am. J. Epidemiol., 2005, 161, 15-26.

31. McCrory C., Layte R., Breastfeeding and risk of overweight and obesity at nine-years of age. Soc. Sci. Med., 2012, 75, 323-330.

32. Mesquita D.N., Barbieri M.A., Goldani H.A.S, Cardoso V.C., Goldani M.Z., Kac G., Silva A.A.M., Bettiol H., Cesarean section is associated with increased peripheral and central adiposity in young adulthood: Cohort Study. PLoS One, 2013, 8(6) ${ }^{\mathrm{o}}$ :e66827. DOI:10.1371/journal.pone.0066827.

33. Michels K.B., Willett W.C., Graubard B.I., Vaidya R.L., Cantwell M.M., Sansbury L.B., Forman M.R., A longitudinal study of infant feeding and obesity throughout life course. Int. J. Obes., 2007, 31, 1078-1085.

34. Myers J., Exercise and cardiovascular health. Circulation, 2003, 107, 2-5.

35. Owen C.G., Whincup P.H., Kaye S.J., Does initial breastfeeding lead to lower blood cholesterol in adult life? A quantitative review of the evidence. Am. J. Clin. Nutr., 2008, 88, 305-314.
36. Owen C.G., Whincup P.H., Gilg J.A., Cook D.G., Effect of breast feeding in infancy on blood pressure in later life: systematic review and meta-analysis. BMJ, 2003, 327, 1189-1195.

37. Owen C.G., Whincup P.H., Odoki K., Gilg J.A., Cook D.G., Infant feeding and blood cholesterol: a study in adolescents and a systematic review. Pediatrics, 2002, 110, 597-608.

38. Parikh N.I., Hwang S.J., Ingelsson E., Benjamin E.J., Fox C.S., Vasan R.S., Murabito J.M., Breastfeeding in infancy and adult cardiovascular disease risk factors. Am. J. Med., 2009, 122, 656-663.

39. Phillips D., Walker B., Reynolds R., Flanagan D., Wood P., Osmond C., Barker D., Whorood Ch., Low birth weight predicts elevated plasma cortisol concentration in adults from 3 populations. Hypertension, 2000, 35, 1301-1306.

40. Ravelli A.C., van der Meulen J.H., Osmond C., Barker D.J., Bleker O.P., Infant feeding and adult glucose tolerance, lipid profile, blood pressure and obesity. Arch. Dis. Child, 2000, 82, 248-252.

41. Schmid M.A., von Rosen-von Hoewel J., Martin-Bautista E., Szabo E., Campoy C., Decsi T., Morgan J., Gage H., Koletzko B., Raats M., Infant feeding and the concept of early nutrition programming: a comparison of qualitative data from four European countries. Adv. Exp. Med. Biol., 2009, 646, 183-187.

42. Swinburn B.A., Caterson I., Seidell J.C., James W.P.T., Diet, nutrition and the prevention of excess weight gain and obesity. Public Health Nutr., 2004, 7, 123-146.

43. Virdis A., Giannarelli C., Neves M.F., Taddei S., Ghiadoni L., Cigarette smoking and hypertension. Curr. Pharm. Des., 2010, 16, 2518-2525.

44. Walburg V., Goehlich M., Conquet M., Callahan S., Schölmerich A., Chabrol H., Breast feeding initiation and duration: comparison of French and German mothers. Midwifery, 2010, 26, 109-115.

45. World Health Organization. 2001. The optimal duration of exclusive breastfeeding. A systematic review. Available online at: [http://whqlibdoc.who.int/hq/2001/WHO_NHD_01.08.pdf] (accessed 4 April 2014).

46. World Health Organization. 2011. Global status report on noncommunicable diseases 2010. Available online at: [http://whqlibdoc.who.int/publications/2011/9789240686458_eng.pdf?ua=1] (accessed 4 April 2014).

Submitted: 24 March 2015. Revised: 14 July and 14 August 2015. Accepted: 27 August 2015. Published on-line: 25 May 2016. 